\title{
Implications of white matter damage in amyotrophic lateral sclerosis (Review)
}

\author{
TING ZHOU $^{1,2}$, TINA KHORSHID AHMAD ${ }^{1}$, KIANA GOZDA $^{1}$, \\ JESSICA TRUONG $^{1}$, JIMING KONG $^{2}$ and MICHAEL NAMAKA ${ }^{1-5}$
}

\begin{abstract}
${ }^{1}$ College of Pharmacy, Rady Faculty of Health Sciences, University of Manitoba, Winnipeg, MB R3E 0T5;
${ }^{2}$ Department of Human Anatomy and Cell Science, College of Medicine, Rady Faculty of Health Sciences, University of Manitoba, Winnipeg, MB R3E 0J9, Canada; ${ }^{3}$ College of Pharmacy, Third Military Medical University, Chongqing 400038, P.R. China; ${ }^{4}$ Department of Medical Rehabilitation, College of Medicine, Rady Faculty of Health Sciences, University of Manitoba, Winnipeg, MB R3E 0T6; ${ }^{5}$ Department of Internal Medicine, College of Medicine, Rady Faculty of Health Sciences, University of Manitoba, Winnipeg, MB R3E 1R9, Canada
\end{abstract}

Received January 28, 2017; Accepted June 9, 2017

DOI: $10.3892 / \mathrm{mmr} .2017 .7186$

\begin{abstract}
Amyotrophic lateral sclerosis (ALS) is a fatal neurodegenerative disease, which involves the progressive degeneration of motor neurons. ALS has long been considered a disease of the grey matter; however, pathological alterations of the white matter (WM), including axonal loss, axonal demyelination and oligodendrocyte death, have been reported in patients with ALS. The present review examined motor neuron death as the primary cause of ALS and evaluated the associated WM damage that is guided by neuronal-glial interactions. Previous studies have suggested that WM damage may occur prior to the death of motor neurons, and thus may be considered an early indicator for the diagnosis and prognosis of ALS. However, the exact molecular mechanisms underlying early-onset WM damage in ALS have yet to be elucidated. The present review explored the detailed anatomy of WM and identified several pathological mechanisms that may be implicated in WM damage in ALS. In addition, it associated the pathophysiological alterations of WM, which may contribute to motor neuron death in ALS, with similar mechanisms of WM damage that are involved in multiple sclerosis (MS).
\end{abstract}

Correspondence to: Professor Michael Namaka, College of Pharmacy, Rady Faculty of Health Sciences, University of Manitoba, Apotex Centre, 750 McDermot Avenue, Winnipeg, MB R3E 0T5, Canada

E-mail:mike.namaka@ad.umanitoba.ca

Professor Jiming Kong, Department of Human Anatomy and Cell Science, College of Medicine, Rady Faculty of Health Sciences, University of Manitoba, 745 Bannatyne Avenue. Winnipeg, MB R3E 0J9, Canada

E-mail: jiming.kong@umanitoba.ca

Key words: amyotrophic lateral sclerosis, white matter damage, molecular mechanism, neuroimaging techniques, therapeutic intervention
Furthermore, the early detection of WM damage in ALS, using neuroimaging techniques, may lead to earlier therapeutic intervention, using immunomodulatory treatment strategies similar to those used in relapsing-remitting MS, aimed at delaying WM damage in ALS. Early therapeutic approaches may have the potential to delay motor neuron damage and thus prolong the survival of patients with ALS. The therapeutic interventions that are currently available for ALS are only marginally effective. However, early intervention with immunomodulatory drugs may slow the progression of WM damage in the early stages of ALS, thus delaying motor neuron death and increasing the life expectancy of patients with ALS.

\section{Contents}

1. Introduction

2. WM anatomy

3. Molecular mechanisms involved in the pathogenesis of WM damage in ALS

4. Therapeutic strategies aimed to attenuate or delay WM damage and disease progression

5. Conclusion

\section{Introduction}

Amyotrophic lateral sclerosis (ALS) is a fatal neurodegenerative disease, involving the progressive degeneration of upper and lower motor neurons. ALS is also known as Lou Gehrig's disease, after the baseball player Lou Gehrig who was diagnosed with the disease (1). ALS can be classified as sporadic (sALS), which represents $\sim 90 \%$ of all ALS cases, and familial (fALS), which accounts for the remaining $10 \%$ of cases (2). Sexual dimorphism has been suggested to be involved in ALS disease onset and progression (3), and the incidence and prevalence of ALS is greater in males compared with in females $(4,5)$. Exposure to environmental toxins, such 
as pesticides, has been considered a key risk factor for ALS; however, further studies are required to elucidate the implication of environmental factors in ALS development (6). ALS is the most common motor neuron disease in adults, and its onset is characterized by distal weakness in the arms or legs, indicative of lower motor neuron involvement. Muscular weakness limits the use of muscles for the execution of voluntary and involuntary movements, thus causing muscular atrophy, eventually leading to respiratory muscle failure and death (7). As the disease progresses into the later stages, patients also experience a progressive decline of cognitive function. In the later stages of ALS, the ocular muscles controlling vision are usually the last to be affected (1).

The primary focus of clinical management for patients with ALS is the symptomatic management of the disease using conventional pharmacological agents, as no cure is currently available. However, non-conventional approaches, including radiotherapy, muscle stretching and nutritional management, have also been employed to alleviate the pain, respiratory dysfunction, psychiatric/cognitive disturbances, nutritional deficits and sleep-related dysfunctions associated with ALS (8). Clinical trials for ALS started in the 1980s; however, the majority of experimental drugs proved to be ineffective with the exception of riluzole, which was reported to marginally extend the lifespan of the patients $(1,9)$.

ALS is most commonly referred to as a motor neuron disease, due to the activation of abnormal programmed cell death signaling pathways during the pathogenesis of the disease, leading to the death and degeneration of motor neurons (10). ALS has been primarily considered a disease of the grey matter involving motor neuron degeneration; however, pathological alterations in the white matter (WM) have been reported to be more pronounced compared with those in motor neuron structures (11). In addition, WM pathophysiological processes have been detected during the early stages of ALS, prior to the appearance of clinical symptoms (12). WM is predominantly composed of myelinated and unmyelinated neuronal axons organized into specific tracts with surrounding glial cells (13). The term 'white matter' arises from the white color of the lipids, which are the main constituents of myelin. Myelin has a water content of $\sim 40 \%$; the dry mass is composed of $70-85 \%$ lipid (14) and $15-30 \%$ protein (15). Among the main proteins found in myelin are proteolipid protein $(\sim 50 \%)$, myelin basic protein $(\sim 30 \%)$ and minor proteins, including myelin oligodendrocyte glycoprotein, 2',3'-cyclic-nucleotide 3'-phosphodiesterase and myelin-associated glycoprotein $(<1 \%)(16)$. The WM of the central nervous system (CNS) is susceptible to anoxia, trauma and autoimmune processes (17). WM damage can be induced by primary and secondary diseases associated with ischemia, inflammation, trauma and hypoxia (13). WM damage has been reported to contribute to the motor and neurological deficits associated with cognitive impairment in neurological conditions, including ALS (18), Alzheimer's disease (19), Huntington's disease (20), progressive supra-nuclear palsy (21) and multiple sclerosis (MS) (22). The severity of WM damage increases with age, leading to decreased cognitive abilities and slower conduction velocity of electrical impulses during physiological functioning (23).

The molecular mechanisms involved in WM damage vary, and include alterations in toll-like receptor-3 expression (24), absorption of Clostridium perfringens $\varepsilon$-toxin (25) and glutamate excitotoxicity during secondary spinal cord (SC) injury (26). Neuropathological alterations of the WM, including axonal degeneration and oligodendrocyte loss $(27,28)$, have been reported in patients with ALS. A previous study using multi-modal magnetic resonance imaging demonstrated that cortical thinning and WM degeneration were associated with cognitive and behavioral impairments in motor neuron diseases (29), whereas significant WM differences have been identified between male and female patients with ALS (30).

The exact molecular mechanisms underlying WM damage in ALS have yet to be elucidated. The presence of clinical and pathological similarities between patients with ALS and MS suggests that a similar WM pathology may be implicated in the diseases $(13,31)$. Typical symptoms of patients with MS include disability, incontinence, limb tremor, pain, spasms, fatigue and spasticity (32). Patients with ALS also display some of the common symptoms of MS; however, typical ALS manifestations also include severe muscle weakness, fasciculation, bulbar symptoms and severe respiratory abnormalities (33).

MS is an autoimmune disease, which is characterized by the immune destruction of the myelin sheath surrounding brain and SC neurons, leading to axonal and neuronal loss. Damaged myelin disrupts the conduction of electrical signals along neural fibers, which is essential for the maintenance of normal functions. Therefore, patients with MS suffer numerous neurological disabilities that negatively impact their quality of life. At present, no cure for MS is available, due to the inability to repair damaged myelin (34). Brain derived neurotrophic factor (BDNF) is a neurotrophin, which has demonstrated beneficial effects during remyelination processes and myelin repair; however, its actions can be hampered by the overexpression of its transcriptional repressor, methyl CpG binding protein 2 (MeCP2) $(34,35)$. Despite the significant differences between MS and ALS, the overlapping symptoms and pathological alterations suggest that the progressive degeneration of central axons may be a critical process in the diseases.

Defects in several genes involved in axonal transport may contribute to axonal loss in MS and ALS (36). Notably, pathogenic mechanisms similar to those responsible for the development of neuroinflammation, excitotoxicity and axonal dysfunction in MS have also been identified in ALS (31). A previous study indicated that first-degree relatives of patients with MS had a greater risk of developing ALS and vice versa, thus suggesting that similar genes may predispose families to MS and ALS (37). Specifically, inflammatory T-lymphocytes, including $\mathrm{T}$ helper (Th) 1 and Th17, and the production of inflammatory mediators, including interleukin 6 , have been reported to drive the inflammatory cascade implicated in the neurological deficits present in patients with ALS and MS (38). Therefore, research has turned to other neurodegenerative diseases, including MS, in order to advance the understanding of WM damage associated with ALS and promote the development of more effective therapeutic strategies $(13,39)$. The present review discussed the key molecules that have been implicated in the common mechanisms of WM damage in MS and ALS. In addition, current therapeutic strategies for the management of ALS were also addressed. 


\section{WM anatomy}

The WM of the CNS contains axon bundles ensheathed by myelin, which is produced by oligodendrocytes and serves as an insulator, thus facilitating the propagation of electrical impulses along the nerve axons. There are three predominant WM tracts in the CNS, composed of projection, association and commissural tracts (40). Conversely, the CNS grey matter largely contains neuronal cell bodies, dendrites, glial cells and synapses (41). Myelin is an insulating substance, which is essential for the propagation of electrical impulses along nerve axons, and is required for the physiological functioning of the nervous system (42). The myelin sheath surrounding the nerve axons in the WM tracts serves a critical role in relaying messages from the brain to the various areas of the body; it also coordinates grey matter communication between areas of the CNS (43). Nerve axons are the predominant component of WM. They are long projections that originate from the neuronal cell body and serve to transmit information in the form of electrical impulses. In addition, nerve axons transport nutrients essential for the health and physiological function of the axons and the neuronal cell bodies (44).

In the CNS, glial cells, including oligodendrocytes and astrocytes, are critical for the maintenance of axonal integrity (45). Oligodendrocytes maintain the structural integrity and functionality of myelin, and the lipid-rich myelin sheath ensures the speed and reliability of electrical transmission (46). Astrocytes are the most prevalent type of glial cell in the CNS. WM astrocytes differ from grey matter astrocytes in morphology, development and function. WM astrocytes are mainly in charge of maintaining the neuronal-glial homeostatic equilibrium, participate in oligodendrocyte lineage differentiation, provide energy supply and nutritional support to the nervous tissue by delivering trophic factors and iron, and are involved in immune and inflammatory processes (13). Although the functional significance of WM glia has yet to be fully elucidated, previous studies have reported that oligodendrocyte and astrocyte dysfunction is implicated in the pathogenesis of neurological disorders, including MS (47), ischemic stroke (40), Huntington's (20) and Alzheimer's disease (48), schizophrenia (49), psychiatric disorders (50) and ALS (51).

Recently, ALS oligodendrocytes were demonstrated to contribute to motor neuron death, through a superoxide dismutase (SOD) 1-dependent mechanism (52), whereas oligodendrocyte degeneration has been reported to occur prior to disease onset. New oligodendrocytes are formed to compensate for the loss; however, they fail to mature, thus resulting in progressive demyelination (52). Furthermore, axonal demyelination has been directly associated with ALS deterioration (53). Therefore, oligodendrocyte dysfunction is considered as a major factor contributing to neuronal degeneration, with relevance to diseases including ALS $(28,54)$. Notably, the glial pathology in ALS, including oligodendrocyte degeneration and impaired maturation, and its involvement in neurodegeneration, is analogous to the pathology displayed in MS (28).

3. Molecular mechanisms involved in the pathogenesis of

\section{WM damage in ALS}

Biological targets of ALS pathology. Several abnormal biological processes have been suggested to be involved in the mechanisms underlying the pathogenesis of ALS (55), thus making it a very complex multi-system and multi-syndrome disorder, for which no single cause can be identified (Figs. 1 and 2). Considerable progress has been made in the investigation of the genetic aspect of ALS pathophysiology. Several genes have been demonstrated to be involved in fALS, including chromosome-9 open reading frame 72 (56), SOD1 (57), coiled-coil-he lix-coiled-coil-helix domain containing 10 (58), Matrin-3 (59), tumor necrosis factor (TNF) receptor-associated factor family member-associated nuclear factor- $\kappa \mathrm{B}$ activator-binding kinase 1 (60), TAR DNA-binding protein (61), fused in sarcoma (62), optineurin (63), Valosin-containing protein (64), ubiquilin 2 (65), sequestosome 1 (66) and profilin $(2,67,68)$. Recently, mutations in the NIMA related kinase 1 gene were associated with ALS (69). With the development of genome sequencing techniques, the number of genes implicated in ALS pathogenesis is increasing, thus suggesting the complexity of the disease, and explaining the elusiveness of a cure. sALS and fALS are the predominant types of ALS, and appear to share some similar pathophysiological mechanisms, including oxidative stress, excitotoxicity, aggregate formation, inflammation and neurofilament disorganization (70,71).

Notably, the mechanisms underlying early-onset WM pathology in MS are similar to those responsible for early-onset WM damage prior to motor neuron death in $\operatorname{ALS}(13,72,73)$. Therefore, elucidation of the pathological mechanisms involved in MS-induced WM damage may provide useful insight to advance the understanding of certain aspects of ALS. Furthermore, novel therapeutic approaches that target WM pathology in the early stages of ALS, may have the potential to delay the progression of the disease and the onset of motor neuron death.

Mitochondrial damage and oxidative stress. Mitochondria are the primary site of ATP production; they also have a major role in the maintenance of $\mathrm{Ca}^{2+}$ homeostasis, the production of free radicals and the regulation of intrinsic apoptotic pathways $(74,75)$. Therefore, mitochondrial dysfunction may be involved in the initial degenerative processes of ALS (76).

Reactive oxygen species (ROS) are byproducts of aerobic metabolism. The cumulative production of ROS results in oxidative stress, which causes mitochondrial damage. ROS can induce mitochondrial DNA mutations, impair the mitochondrial respiratory chain, alter mitochondrial membrane permeability and ultimately cause cell death (77). Previous studies have suggested the time- and dose-dependent involvement of ROS, including superoxide $\left({ }^{\circ} \mathrm{O}_{2}{ }^{-}\right)$and hydroxyl ( $(\mathrm{OH})$ radicals, and hydrogen peroxide $\left(\mathrm{H}_{2} \mathrm{O}_{2}\right)$, in mitochondrial damage driving motor neuron degeneration (Fig. 1) $(78,79)$. In sALS and fALS, post-mortem and biopsy samples from the SC and motor neurons revealed abnormalities in mitochondrial structure, number and localization, which were associated with defects in respiratory chain complexes (80). Furthermore, elevated ROS production and mitochondrial dysfunction have also been observed in SC samples isolated from a rat model of sALS (81). 


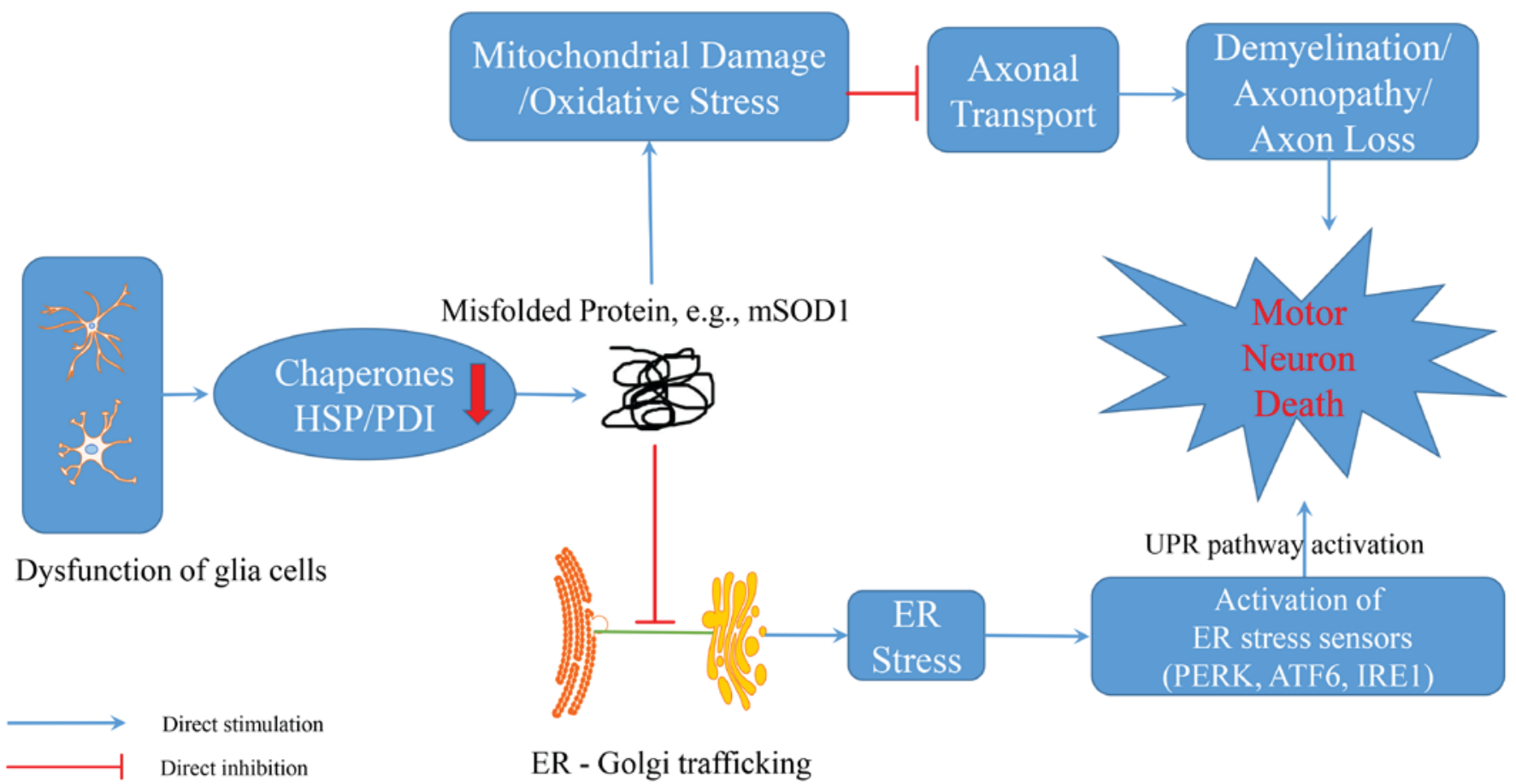

Figure 1. Schematic representation of the effects of mitochondrial damge and ER stress in ALS pathogenesis. Dysfunction of glial cells results in decreased levels of chaperone proteins, including HSPs and members of the PDI family. The impaired expression of chaperone proteins results in protein misfolding, which impairs ER-Golgi apparatus trafficking. The UPR signaling pathway is activated due to ER stress caused by impaired ER-Golgi trafficking, and initiates cell apoptosis. In addition, mutations in superoxide dismutase 1 cause mitochondrial damage and oxidative stress, ultimately leading to abnormalities in axonal transportation. ER, endoplasmic reticulum; ALS, amyotrophic lateral sclerosis; HSP, heat shock protein; PDI, protein disulphide isomerase; UPR, unfolded protein response; PERK, protein kinase R-like endoplasmic reticulum kinase; ATF, activating transcription factor; IRE, inositol-requiring enzyme.

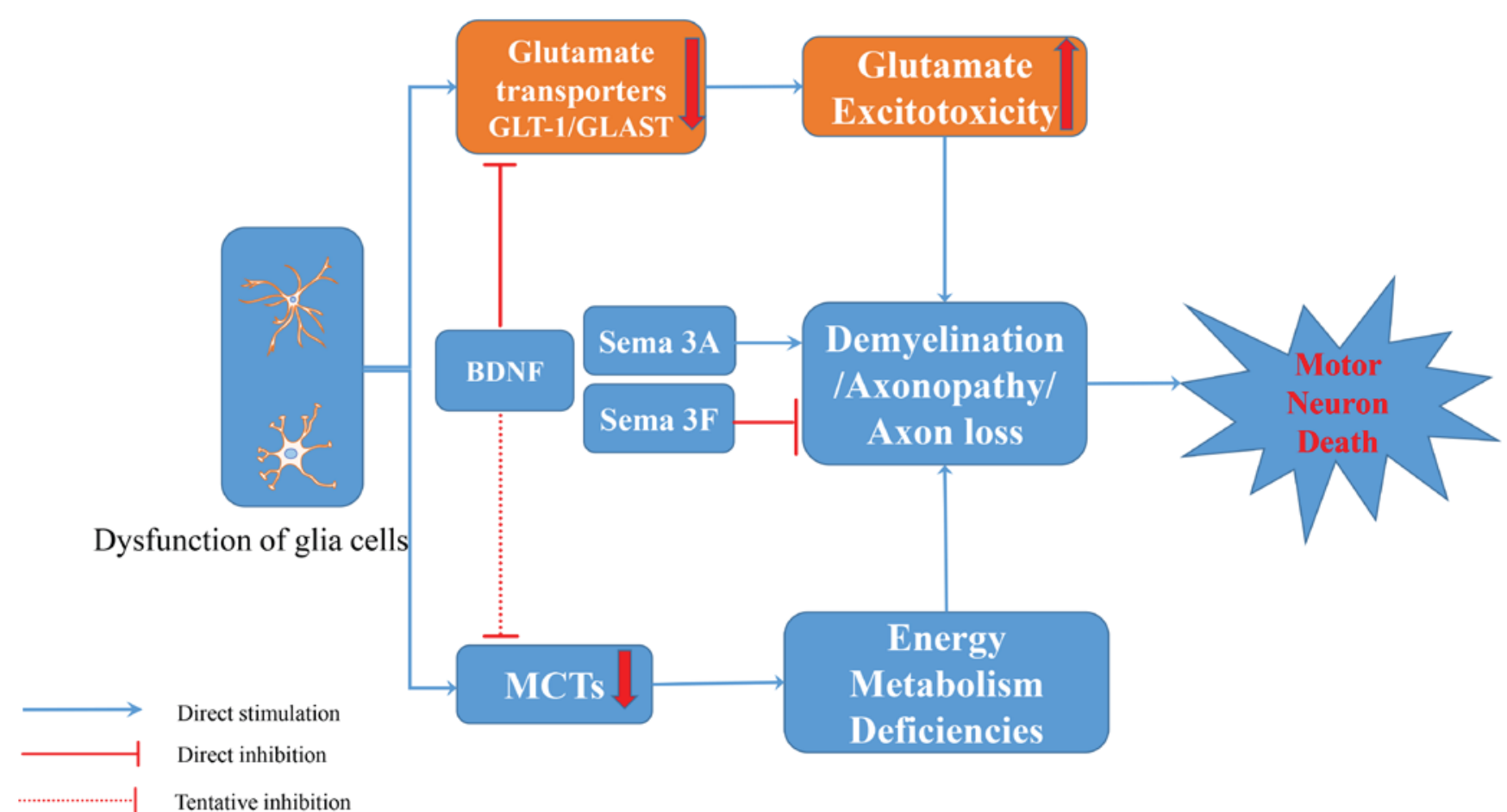

Figure 2. Schematic representation of the effects of glutamate excitotoxicity, energy metabolism deficiency and axonopathy in ALS pathogenesis. Dysfunction of glial cells results in the decreased expression of glutamate transporters, including GLT-1 and GLAST, leading to glutamate excitotoxicity. Although excitotoxicity can induce axonopathy and neuronal degeneration, interventions aimed at increasing BDNF production can attenuate excitotoxicity, enhance axonal repair and regrowth and eventually ameliorate the degeneration of motor neurons. Furthermore, glial cell dysfunction results in the downregulation of MCTs, thus impairing the axonal energy supply, which leads to axon loss and motor neuron degeneration. The BDNF signaling pathway is also implicated in MCT expression; however, further studies are required to investigate the molecular mechanisms that are involved. In addition, class 3 semaphorins are involved in oligodendroglial migration, and their dysregulation is implicated in remyelination impairments and axonopathy. ALS, amyotrophic lateral sclerosis; GLT, glutamate transporter; GLAST, glutamate aspartate transporter; BDNF, brain-derived neurotrophic factor; MCT, monocarboxylate transporter; Sema, semaphorin. 
Cell type-specific mitochondrial damage has been demonstrated to contribute to the pathogenesis of ALS: Mitochondrial dysfunction in astrocytes has been associated with a neurotoxic phenotype that impairs motor neuron survival (82), with a mechanism that may involve mutant (m)SOD1 aggregation. mSOD1 aggregates cause mitochondrial damage due to a decrease in the antioxidant activity of the enzyme, thus resulting in ROS accumulation. In addition, mSOD1 may potentiate the formation of ${ }^{\circ} \mathrm{OH}$, as suggested by the increased levels of oxidation products in mSOD1-transfected mice compared with controls (83). Furthermore, mSOD1 protein aggregates may be responsible for impairments in axonal transport, neurotrophic factor supply, endoplasmic reticulum (ER) stress and apoptosis in glial cells $(84,85)$. mSOD1 is present in $\sim 20 \%$ of patients with fALS and $\sim 3 \%$ of patients with sALS (86); however, oxidative stress and mitochondrial damage are also present in non-SOD1-linked ALS cases (87).

ER stress. ER is an intracellular organelle that is responsible for protein quality control, as it ensures that proteins are correctly synthesized, folded, packaged and delivered in the appropriate locations. Under ER stress conditions, the unfolded protein response (UPR) signaling pathway is activated to restore cellular integrity or initiate apoptosis (88). Three ER stress sensors mediate the UPR, namely protein kinase R-like ER kinase (PERK), activating transcription factor 6 (ATF6) and inositol-requiring enzyme 1 (IRE1) (89). ER stress can be triggered by the accumulation of unfolded or misfolded proteins in the ER lumen, and by other mechanisms, including the inhibition of ER-to-Golgi apparatus transport. Notably, mSOD1 has been implicated in impaired ER-to-Golgi trafficking, which represents an early cellular disturbance before the induction of ER stress, Golgi fragmentation (90), mSOD1 aggregation and cell apoptosis (Fig. 1) (91).

Chaperone proteins, including heat shock proteins (HSP) and members of the protein disulphide isomerase (PDI) family, ensure proteins are folded correctly, and may have a cytoprotective role in ALS (92). Low levels of HSP in motor neurons increase their susceptibility to stress, thus increasing their vulnerability to cell death processes. Neuronal HSP levels depend upon the neuronal and glial production of HSP (93). Notably, periventricular WM damage induced by iron accumulation in oligodendrocytes may increase ER stress and mitochondrial disruption, ultimately resulting in glial cell death (94). Therefore, WM damage may be responsible for HSP deficits and increased ER stress, which eventually lead to motor neuron apoptosis.

The UPR signaling pathway has been implicated in WM tract myelination under normal physiological conditions. The ER stress sensors PERK, ATF6 and IRE1 are activated under physiological conditions, resulting in the upregulation of downstream molecules, including PDI, 78 kDa glucose-related protein and $94 \mathrm{kDa}$ glucose-related protein. These molecules have been associated with oligodendrocyte damage, reduced axon numbers and demyelination, which are associated with ALS progression $(95,96)$. Notably, increased PDI expression has been reported in WM microglia of the SC and in astrocytes of the SC ventral horn in an ALS mouse model, thus suggesting that the UPR in WM glia may occur early in the phase of motor neuron degeneration during ALS (97).
Motor neurons in mice with fALS were revealed to be prone to ER stress and demonstrated upregulated ER stress marker expression accompanied by axonal degeneration (98). These studies suggested that the early mechanisms of WM damage in ALS may induce ER stress, which, in turn, may activate the UPR signaling pathway, ultimately resulting in motor neuron degeneration and death. Therefore, it may be hypothesized that therapeutic strategies aimed at attenuating or delaying WM damage may have potential in reducing motor neuron death and disease progression in patients with ALS, thus increasing their life expectancy.

Glutamate excitotoxicity. Accumulating evidence suggests that glutamate excitotoxicity may be implicated in the mechanisms of neuronal degeneration in ALS (99-101); imbalances between excitatory and inhibitory neurotransmission may contribute to the pathogenesis of the disease. Glutamate is the primary excitatory amino acid neurotransmitter in the CNS. Glutamate excitotoxicity has been associated with oligodendrocyte apoptosis and may induce WM degeneration following SC injury (26). An increase in excitatory neurotransmission, as indicated by increased levels of glutamine, has been reported in the motor cortex and WM of patients with ALS compared with healthy controls (101). Glutamine synthesis is catalyzed by the enzyme glutamine synthetase from glutamate and ammonia (102), and glutamine production is used as a marker of glutamate levels to detect glutamate-induced excitotoxicity.

Astrocyte-mediated cell-specific excitotoxicity has also been implicated in the pathogenesis of ALS. Astrocytes express two glutamate transporters (GLTs): GLT-1, also known as excitatory amino acid transporter (EAAT) 2, and glutamate aspartate transporter, also known as EAAT1, which participate in extracellular glutamate homeostasis and neuronal reuptake (Fig. 2) (103). Glutamate excitotoxicity, mediated by non-N-methyl-D-aspartate receptors, has been reported to cause axonopathy, including axonal swelling, cytoskeletal disruption and neurofilament accumulation, in the distal axonal segments of SC motor neurons (104). Studies suggested that glutamate excitotoxicity may be implicated in axonopathy, WM damage and long-term cognitive deficits in patients with ALS. Therefore, neuroprotective agents, including vasoactive intestinal peptide, may attenuate excitotoxic damage, and also increase BDNF production to promote secondary repair and axonal regrowth, thus limiting WM damage and ameliorating motor neuron degeneration $(105,106)$.

The cell-specific effects of astrocytes have also been reported to participate in the activation of protein kinase $\mathrm{C}$ and mitogen-activated protein kinase (MAPK) pathways to induce neuroprotection $(105,106)$. These results suggested that astrocyte activation may differentially facilitate or prevent motor neuron degeneration. Further studies are required to elucidate the differential functions of astrocytes in the pathology of degenerative diseases, including ALS (107) and MS (108).

Energy metabolism deficiencies. The human brain utilizes glucose and monocarboxylates, such as lactate, as primary energy sources. Lactate accounts for $\sim 33 \%$ of the total energy substrates used by the brain, representing a more important fuel source for brain metabolism than glucose (109). Monocarboxylate transporters (MCTs) are responsible for 
lactate and pyruvate transport. In the brain, three MCT isoforms have been identified, namely MCT1, MCT2 and MCT4, which are implicated in lactate flux in the CNS (109). MCT1 is expressed in astrocytes and oligodendrocytes, whereas MCT4 is expressed exclusively in astrocytes. WM astrocytes and oligodendrocytes are critical for the production and maintenance of myelin (110), and the delivery of essential energy (111), thus supporting the physiological function of the CNS. Oligodendrocytes exhibit higher MCT1 expression, and increased lactate oxidation and lipid synthesis compared with astrocytes (13). Therefore, oligodendrocyte dysfunction may contribute to motor neuron degeneration and death in ALS. Notably, oligodendrocyte pathology becomes apparent prior to disease onset and persists during disease progression $(45,112)$. A previous study suggested that oligodendroglia may support axon survival and function through a myelin-independent mechanism, whereas deficiencies in energy metabolites may underlie neurodegeneration (113). In human studies and preclinical mouse ALS models, MCT1 expression was revealed to be decreased in affected brain regions, resulting in insufficient energy supply to the axons, thus leading to axon loss and motor neuron degeneration and death $(13,111,114)$. These findings suggested that the molecular mechanisms involved in early-onset WM damage in ALS may also contribute to motor neuron death (Fig. 2). Therefore, therapeutic strategies aimed at attenuating early-onset WM damage may have potential for the effective treatment of patients with ALS.

Unlike MTC1 or MTC4, MTC2 is highly expressed in the dendrites and axons of CNS neurons (115). Notably, a marked downregulation in the axonal expression of glucose transporter 3 (GLUT3) and MCT2 has been reported in WM samples isolated from MS lesions, and has been suggested to impede the supply of essential nutrients (116). Furthermore, Robinet and Pellerin (117) suggested that BDNF signaling may be implicated in the upregulation of MCT2 expression in brain neurons following acute exercise; BDNF may increase neuronal MCT2 expression through the translational regulation of phosphatidylinositol-4,5-bisphosphate 3-kinase (PI3K)/Akt/mechanistic target of rapamycin/S6, p38 MAPK, and p44/p42 MAPK pathways (117).

Axonopathy. Motor neuron axonopathy has been proposed as an early initiating mechanism of ALS. Motor neuron pathology in ALS has been suggested to begin, at distal axon sites and proceeds in a retrograde manner, eventually leading to motor neuron degeneration, a hypothesis termed the 'dying back' mechanism (27). Axonopathy has also been demonstrated in animal models of ALS, including zebrafish (118), mice (119) and rats (120). In rats carrying the SOD1-G93A mutation, mitochondrial accumulation of mSOD1 was observed in motor neuron axons in discrete clusters located at regular intervals, instead of a homogeneous axonal distribution (120). Overexpression of mSOD1 (118), and excitotoxicity (104), have been suggested to trigger axonopathy. In addition, excitotoxic axonopathy has been associated with the aberrant colocalization of phosphorylated and dephosphorylated neurofilament proteins, which may subsequently induce axonal transport disruptions and swelling. In addition, axonopathy has been associated with abnormalities within the glial environment (121). Fast-fatigable motor neurons are highly susceptible to axonal degeneration, which is associated with deficiencies in protein and lipid supply to axons $(27,122)$. As aforementioned, oligodendrocytes regulate axonal myelination to maintain axonal function, whereas astrocytes provide structural and trophic support for neurons. Abnormal glial-axonal interactions have been reported to be implicated in axonal swelling, neurofilament perturbations and microtubule transport defects during axonal degeneration (123).

Semaphorin proteins serve as axonal growth signaling cues and are responsible for axon guidance and neurofilament organization during nervous system development (124). Class 3 semaphorins are involved in oligodendroglial migration and remyelination. Semaphorin (Sema) 3A is a repulsive guidance cue for neuronal and glial cells, and induces the redistribution and depolymerization of actin filaments that results in growth cone collapse. In addition, Sema3A is expressed in MS lesions, where it impairs the recruitment and differentiation of oligodendrocyte precursor cells (OPCs) and inhibits remyelination $(125,126)$. Conversely, Sema3F is an attractive guidance cue, which assists OPC recruitment and promotes axonal remyelination $(126,127)$. The roles of Sema3A have also been investigated in ALS: In an ALS mouse model, Sema3A and its receptor neuropilin 1 were demonstrated to induce distal axonopathy (128). Furthermore, in humans, Sema3A levels in the motor cortex were significantly upregulated in patients with ALS compared with in controls. These results suggested that the increase in Sema3A expression may be implicated in axonal degeneration, and may be associated with the axonopathy and denervation that are observed in patients with ALS (129). Sema3A, and other class 3 semaphorins, are important regulators of axonal remyelination and of the immune responses that govern neuronal regeneration (Fig. 2) (130). Therefore, the inhibition of Sema3A may have potential as a novel therapeutic strategy for the treatment of patients with ALS. According to the 'dying back' hypothesis regarding motor neuron pathology (27), it may be necessary to focus on motor axons and nerve terminals in order to effectively delay or prevent motor neuron degradation (131).

Neuronal cell death. Several mechanisms, including oxidative stress, the aggregation of misfolded and mutant proteins, and excitotoxicity, may disrupt the homeostasis of motor neurons, ultimately causing cell death. MeCP2 is a nuclear protein with numerous biological functions, which serves a critical role in myelin damage in neurological conditions, including epilepsy (132) and MS (34). MeCP2E1 and MeCP2E2 are the two predominant isoforms of $\mathrm{MeCP} 2$ that exert diverse biological effects on neuronal survival. Previous studies have revealed that $\mathrm{MeCP} 2 \mathrm{E} 2$ promotes neuronal death and apoptosis; however, these effects may be inhibited by Forkhead box protein G1 and Akt, which enhance neuronal survival $(133,134)$.

$\mathrm{MeCP} 2 \mathrm{E} 1$ has been reported to repress BDNF transcription, thus resulting in the failure of myelin repair mechanisms (34). BDNF serves a role in myelin repair and promotes the health of neurons, astrocytes and oligodendrocytes; therefore, BDNF deficiencies have been implicated in the pathological mechanisms of ALS $(135,136)$. Notably, BDNF serum levels have been revealed to be significantly decreased in patients with ALS compared with in controls (137). Therefore, BDNF may have potential as a biomarker to reflect disease activity, and may 
serve as a basis for the development of novel therapeutic strategies for ALS treatment (135). Neurotrophic factors, including BDNF, have been reported to exert beneficial effects in mouse models of ALS: Treatment of SOD1-G93A transgenic mice with neurotrophic factors has been reported to inhibit neuromuscular junction degeneration, enhance axon survival, delay the onset of ALS and prolong the average lifespan of the mice $(138,139)$.

In ALS, apoptosis is the most common form of motor neuron death, and involves pro- and anti-apoptotic gene expression, caspase activation, cytochrome $c$ release and apoptosis-inducing factor (AIF) nuclear translocation (140-142). Notably, in patients with ALS, apoptotic processes are not restricted to motor neurons, but also affect other neuronal and non-neuronal components of the CNS (143). A previous study reported increased neuronal apoptosis, accompanied by an increase in glial fibrillary acidic protein-positive astrocytes and increased microglia activation in the white and grey matter of several CNS regions (144). In addition, astrocytes, but not microglia, cortical neurons or myocytes, were suggested to have an integral role in the death of motor neurons in ALS (145).

At least three different molecular pathways have been reported to participate in programed cell death: the mitochondrial pathway, the death receptor pathway and the ER pathway (146). The present review explored only mitochondria-dependent apoptosis, as it is primarily responsible for neuronal and non-neuronal cell death in ALS. The mitochondrial apoptotic pathway is activated during the early stages of ALS, and proapoptotic signaling has been revealed to directly induce neuronal dysfunction (147). B-cell lymphoma (Bcl)-2 family members have also been reported to serve critical roles during apoptosis that lead to motor neuron death, via controlling mitochondrial permeability in ALS models. The expression and distribution of $\mathrm{Bcl}-2$, Bcl-extra large, $\mathrm{Bcl}-2$-associated death promoter (Bad) and Bcl-2-associated $\mathrm{X}$ protein $(\mathrm{Bax})$ are altered in ALS mouse models, thus suggesting the presence of mitochondrial damage $(143,148)$. In addition, inhibition of the PI3K/Akt signaling pathway can directly induce proapoptotic proteins, including Bad and Bax, and thus contribute to the degenerative and apoptotic pathways during ALS pathogenesis (149). Caspase activation and elevated cytosolic cytochrome $c$ levels have also been observed in ALS cell lines, thus indicating that mitochondria-dependent apoptosis may contribute to cell death in ALS (150). However, the altered expression of Bcl-2 family proteins, the inhibition of PI3K/Akt signaling and the activation of caspases may not be the only pathways leading to motor neuron degeneration in ALS, as apoptosis is a complex process, and is known to be induced through numerous pathways (151).

AIF is a key regulator of caspase-independent apoptosis, and its increased expression has been associated with the progression of ALS. AIF has been revealed to co-translocate to motor neuron nuclei with cyclophilin A; following binding with cyclophilin A, AIF may induce mitochondrial membrane permeabilization and cell death in a model of ALS (152). Therefore, proapoptotic signaling may contribute to the neuronal and non-neuronal degeneration that causes WM damage and motor neuron death in ALS. Therefore, inhibition of the mitochondrial apoptotic pathway may have potential as another novel therapeutic approach to suppress myelin damage and/or preserve motor neuron viability and function in patients with fALS (147).

Microbiome. The gut microbiome can influence host biology and contribute to WM damage in CNS disorders. The microbiome-gut-brain axis is responsible for the association between the microbiome and neuroimmune and neuropsychiatric disorders (153), including MS (154,155), autism (156) and ALS (157). The microbiome-gut-brain axis refers to the interactions between the CNS, the gastrointestinal tract and the microorganisms in the gut. Several mechanisms have been suggested to explain the influence of the gut microbiome on brain health (158): Impaired intestinal barrier function has been suggested to promote the passage of toxins from the intestinal lumen into the blood circulation and the brain. A previous study demonstrated that Clostridium perfringens $\varepsilon$-toxin may be responsible for WM damage in the CNS of mice. $\varepsilon$-toxin secreted into the gut was revealed to bypass the blood-brain barrier and cause mature oligodendrocyte death, demyelination and WM injury; these effects were dependent on the expression of myelin and lymphocyte protein proteolipid (25). Notably, $\varepsilon$-toxin has been demonstrated to exert selective toxic effects on oligodendrocytes but not astrocytes, microglia or neurons in primary cultures (25). Furthermore, dysbiosis of the gut microbiota has been reported in patients with MS compared with in healthy controls $(159,160)$, whereas gut-derived neurotoxins have been proposed as a cause of ALS $(161,162)$. In an ALS mouse model (SOD1-G93A), impaired gut integrity and a shift in the profile of the gut microbiome have been observed at the early stages of the disease, and have been reported there to be associated with increased disease severity (163). These findings suggested a potential role for the microbiome in the progression of ALS. However, the precise alterations in the gut microbiome during ALS pathogenesis have yet to be elucidated. Numerous factors, including hygiene, antibiotic usage, microbiota composition, probiotics and diet, have been proposed to influence the link between the gut microbiome and the CNS (153). Understanding the relationship between the gut microbiome and neuroimmunology may aid the development of novel preventative and therapeutic strategies for the treatment of CNS disorders, including ALS.

\section{Therapeutic strategies aimed to attenuate or delay WM damage and disease progression}

Riluzole. Similar mechanisms have been proposed concerning the pathogenesis of WM damage and subsequent disease progression for ALS and MS; however, no cure exists for these chronic diseases. Currently available therapeutic interventions mainly focus on delaying the onset of the disease, slowing its progression and improving the survival rates.

Riluzole is the only drug approved by the US Food and Drug Administration for the treatment of patients with ALS, and it has been clinically available since 1995. However, treatment with riluzole can only marginally improve the neurological symptoms of the patients and prolong their survival by 3-4 months (164), whereas a previous epidemiological study reported that riluzole exerted a beneficial effect only during the first 6 months of therapy, with an apparent reversal of its beneficial effects after the 6-month time point (165). 
The molecular mechanisms underlying the neuroprotective effects of riluzole in ALS have yet to be elucidated. It has been suggested that riluzole may exert its beneficial effects via preventing motor neuron excitotoxicity, through the blockade of voltage-dependent ion channels (166-168). However, riluzole has also been reported to act on astrocytes in the WM to induce neural growth factor production and improve the neuronal survival rate $(168,169)$. In addition, it has been demonstrated to stimulate BDNF release $(170,171)$. A previous study from our group suggested the importance of BDNF during myelin repair, as increased levels of BDNF were revealed to facilitate myelin repair and offer neuroprotection in the CNS (33). Therefore, the enhancing effects of riluzole on BDNF production may also contribute to its neuroprotective effects in patients with ALS.

Riluzole has been demonstrated to reduce inflammation, demyelination and axonal damage, and attenuate the clinical severity of the experimental autoimmune encephalomyelitis (EAE) model of MS, thus suggesting that riluzole may also be beneficial for the treatment of MS (172). A phase II clinical trial is currently in progress for the use of riluzole in patients with MS (173); however, a previous phase II trial in patients with early MS revealed that riluzole was not able to prevent the progression of brain atrophy (174). Furthermore, the acute and chronic treatment of ALS mice with riluzole exerted opposite effects on the production of trophic factors in the CNS, including glial cell-derived neurotrophic factor, BDNF, cardiotrophin-1 (CT-1) and nerve growth factor: Acute treatment with riluzole was revealed to induce trophic factor production in the SC, sciatic nerve and brain, whereas chronic treatment exerted inhibitory effects (169). In the study by Dennys et al (169), riluzole significantly increased CT-1 levels in the SC following 15 days of continuous treatment, which returned to baseline following 30 days of treatment. In addition, riluzole increased brain BDNF levels following 6 and 15 days of treatment, which were significantly decreased following 30 days of treatment.

The levels of released BDNF appear to be a critical factor in ALS pathology, since BDNF has been reported to serve an essential role in the development of pathologic pain (175). Increased BDNF levels have been suggested to induce the development of chronic pain, whereas BDNF deficits may result in the failure of myelin repair mechanisms $(34,176)$. These findings suggested that a delicate equilibrium in the endogenous BDNF levels may be required for the maintenance of myelin repair without the induction of nociception. Therefore, therapeutic schemes that favor the acute effects of riluzole administration, and the close monitoring of BDNF levels may have the potential to improve the therapeutic outcomes of treatment with riluzole.

Other drugs on the market or in clinical trials. As the efficacy of riluzole is only marginal, and its administration can increase survival by only a few months, clinicians suggest that treatment with riluzole should be started at the early stages of the disease in order to maximize its benefits. Novel agents with higher efficacy are currently under investigation, and various administration routes are being evaluated in order to improve the efficacy and minimize the adverse effects of the treatments (177).
Novel experimental drugs are currently being evaluated in preclinical animal models and in human clinical trials (178). Pramipexole (PPX), is a D2/D3-preferring dopamine receptor agonist, which has been demonstrated to exert beneficial effects in the EAE model of MS (179): PPX blocked neuroinflammatory responses, demyelination and astroglial activation in the $\mathrm{SC}$, and it inhibited the production of proinflammatory cytokines and ROS (179). In addition, dexpramipexole (RPPX), which is the R (+) enantiomer of PPX, has also demonstrated neuroprotective effects, via acting directly on mitochondria to stabilize mitochondrial ionic conductance and reduce free radical production, thus inhibiting cell death (180-182). Early phase clinical trials in patients with ALS suggested that RPPX has a promising safety and tolerability profile, and a phase III clinical trial is currently underway to investigate its efficacy in patients with ALS (183).

Pioglitazone is a peroxisome proliferator-activated receptor- $\gamma$ agonist, which has been demonstrated to exert anti-inflammatory and neuroprotective actions. It has been suggested as a potential therapeutic agent for the treatment of MS, due to its ability to reduce TNF- $\alpha$-induced myelin damage and mitochondrial dysfunction (184). In a phase I clinical trial in patients with relapsing remitting MS, treatment with pioglitazone was reported to reduce lesion development in WM, via inhibiting demyelination and axonal degeneration (185). However, pioglitazone did not exert beneficial effects on the survival of patients with ALS, as revealed by a phase II clinical trial evaluating it as an add-on therapy in combination with riluzole (186). However, riluzole was revealed to exert neurotoxic effects at concentrations between 3 and $30 \mu \mathrm{M}$, which may antagonize the neuroprotective effects of several compounds being evaluated in clinical trials, including resveratrol, memantine, minocycline and lithium (187). Therefore, further studies are required, using a group of patients without riluzole treatment to evaluate the neuroprotective potential of novel agents in ALS (187).

Flavonoids are bioactive compounds that are derived from fruit and vegetables. Epigallocatechin-3-gallate is a flavonoid that has been demonstrated to reduce neuroinflammation, and limit demyelination and axonal damage in the EAE model of MS (188) and the SOD1-G93A mouse model of ALS (189). The neuroprotective effects of flavonoids suggest that they may have potential as alternative therapeutic agents for the treatment of neurodegenerative diseases, including MS and ALS (190).

Stem cell transplantation has also been recognized as a potential therapeutic strategy for the treatment of patients with ALS and MS (191). A previous study demonstrated that a neural stem cell (NSC) population isolated from human induced pluripotent stem cells improved the neuromuscular function and increased the life span of ALS mice, following intrathecal or intravenous administration. The results revealed that the transplanted NSCs migrated and engrafted into the CNS, where they improved the production of neurotrophic factors and reduced micro- and macrogliosis (192). Furthermore, a human study demonstrated that transplantation of autologous stem cells into patients with ALS delayed disease progression and increased survival (193). In addition, neural precursor cell transplantation has been reported to 
enhance remyelination in an EAE mouse MS model of extensive demyelination (194). Genetically engineered bone marrow stem cells have also been used to deliver BDNF in EAE mice, and resulted in the significant delay of EAE onset, which was accompanied by a reduction in demyelination and overall clinical severity (195).

ALS is a multi-syndrome disease, which is characterized by extensive genetic and phenotypic variability. Therefore, the discovery of a single agent that can be used for the treatment of all ALS patients is unlikely. Although MS and ALS differ in many aspects, they share a number of common pathogenic features, including inflammation, oxidative stress, mitochondrial dysfunction and WM damage (196). For this reason, early diagnosis, and early interventional therapies that target certain molecular and genetic pathways are urgently required for the treatment of patients with ALS and MS.

\section{Conclusion}

ALS is a complex multi-system and multi-syndrome disease that affects neuronal and non-neuronal populations, and is characterized by the progressive degeneration of motor neurons. Several pathological mechanisms are involved in WM damage in ALS, including mitochondrial dysfunction, oxidative stress, neuronal apoptosis, ER stress, glutamate excitotoxicity, energy metabolism defects and axonopathy, which bear a strong similarity to other WM disorders, such as MS (Figs. 1 and 2). Therefore, immunomodulatory agents that are currently available for the treatment of MS may have potential as early treatment options for patients with ALS characterized by early-onset WM damage.

The current review presented a comprehensive evaluation of ALS, discussing motor neuron death as the principal cause of the disease, and examining the impact of early-onset WM damage, which is a common pathology in ALS and MS, as confirmed by neuroimaging techniques (12,197-199). The immune system has been identified as a key regulator of pathological neuronal-glial interactions. However, the exact molecular mechanisms surrounding WM damage in ALS have yet to be elucidated. Although MS and ALS are distinct neurodegenerative CNS diseases, they share common pathogenic features. Therefore, understanding the molecular mechanisms that underlie WM damage in MS may aid the development of improved therapeutic strategies that address the early-onset WM damage occurring in ALS. The identification of potentially important molecular targets, including MeCP2E1, MeCP2E2, BDNF (34) and semaphorin $(200,201)$ in MS may help advance our understanding of the molecular mechanisms underlying the pathogenesis of ALS. Current agents used for the treatment of ALS, including riluzole, and experimental drugs currently in clinical trials do not appear to affect the WM damage that is associated with the disease. Further studies are required to elucidate the roles of WM damage and neuroglial pathology in the development and progression of ALS.

\section{Acknowledgements}

The authors would like to acknowledge the support from the ALS Society of Canada(ALS Canada), the College of Pharmacy at the University of Manitoba, and the Joint Laboratory of Biological Psychiatry between Shantou University Medical College in Guangdong, China and the College of Medicine at the University of Manitoba.

\section{References}

1. Morris J: Amyotrophic lateral sclerosis (ALS) and related motor neuron diseases: An overview. Neurodiagn J 55: 180-194, 2015.

2. Therrien M, Dion PA and Rouleau GA: ALS: Recent developments from genetics studies. Curr Neurol Neurosci Rep 16: 59, 2016.

3. Li R, Strykowski R, Meyer M, Mulcrone P, Krakora D and Suzuki M: Male-specific differences in proliferation, neurogenesis, and sensitivity to oxidative stress in neural progenitor cells derived from a rat model of ALS. PLoS One 7: e48581, 2012.

4. McCombe PA and Henderson RD: Effects of gender in amyotrophic lateral sclerosis. Gend Med 7: 557-570, 2010.

5. Orsini M, Oliveira AB, Nascimento OJ, Reis $\mathrm{CH}$, Leite MA,de Souza JA, Pupe C, de Souza OG, Bastos VH, de Freitas MR, et al: Amyotrophic lateral sclerosis: New perpectives and update. Neurol Int 7: 5885, 2015.

6. Bozzoni V, Pansarasa O, Diamanti L, Nosari G, Cereda C and Ceroni M: Amyotrophic lateral sclerosis and environmental factors. Funct Neurol 31: 7-19, 2016.

7. Talbot K: Motor neurone disease. Postgrad Med J 78: 513-519, 2002.

8. Riva N, Agosta F, Lunetta C, Filippi M and Quattrini A: Recent advances in amyotrophic lateral sclerosis. J Neurol 263: 1241-1254, 2016

9. Mathis S, Couratier P, Julian A, Vallat JM, Corcia P and Le Masson G: Management and therapeutic perspectives in amyotrophic lateral sclerosis. Exp Rev Neurother 17: 263-276, 2017.

10. Martin LJ, Price AC, Kaiser A, Shaikh AY and Liu Z: Mechanisms for neuronal degeneration in amyotrophic lateral sclerosis and in models of motor neuron death (Review). Int J Mol Med 5: 3-13, 2000.

11. Rafałowska J and Dziewulska D: White matter injury in amyotrophic lateral sclerosis (ALS). Folia Neuropathol 34: 87-91, 1996.

12. Sach M, Winkler G, Glauche V, Liepert J, Heimbach B, Koch MA, Büchel C and Weiller C: Diffusion tensor MRI of early upper motor neuron involvement in amyotrophic lateral sclerosis. Brain 127: 340-350, 2004.

13. Li J, Zhang L, Chu Y, Namaka M, Deng B, Kong J and Bi X: Astrocytes in oligodendrocyte lineage development and white matter pathology. Front Cell Neurosci 10: 119, 2016.

14. Aggarwal S, Yurlova L and Simons M: Central nervous system myelin: Structure, synthesis and assembly. Trends Cell Biol 21: 585-593, 2011.

15. Morell P and Quarles RH: Characteristic Composition of Myelin. In: Basic Neurochemistry: Molecular, Cellular and Medical Aspects. Siegel GJ, Agranoff BW, Albers RW, et al (eds). 6th edition. Lippincott-Raven, Philadelphia, PA, 1999.

16. Mallucci G, Peruzzotti-Jametti L, Bernstock JD and Pluchino S: The role of immune cells, glia and neurons in white and gray matter pathology in multiple sclerosis. Prog Neurobiol 127-128: 1-22, 2015.

17. Stys PK: White matter injury mechanisms. Curr Mol Med 4: 113-130, 2004.

18. Sarro L, Agosta F, Canu E, Riva N, Prelle A, Copetti M, Riccitelli G, Comi G and Filippi M: Cognitive functions and white matter tract damage in amyotrophic lateral sclerosis: A diffusion tensor tractography study. AJNR Am J Neuroradiol 32: 1866-1872, 2011.

19. Duan JH, Wang HQ, Xu J, Lin X, Chen SQ, Kang Z and Yao ZB: White matter damage of patients with Alzheimer's disease correlated with the decreased cognitive function. Surg Radiol Anat 28: 150-156, 2006.

20. Della Nave R, Ginestroni A, Tessa C, Giannelli M, Piacentini S, Filippi M and Mascalchi M: Regional distribution and clinical correlates of white matter structural damage in Huntington disease: A tract-based spatial statistics study. AJNR Am J Neuroradiol 31: 1675-1681, 2010.

21. Agosta F, Galantucci S,Svetel M,Lukić MJ, Copetti M,Davidovic K, Tomić A, Spinelli EG, Kostić VS and Filippi M: Clinical, cognitive, and behavioural correlates of white matter damage in progressive supranuclear palsy. J Neurol 261: 913-924, 2014. 
22. Bester M, Lazar M, Petracca M, Babb JS, Herbert J, Grossman RI and Inglese M: Tract-specific white matter correlates of fatigue and cognitive impairment in benign multiple sclerosis. J Neurol 330: 61-66, 2013.

23. Valdés Hernández Mdel C, Booth T, Murray C, Gow AJ Penke L, Morris Z, Maniega SM, Royle NA, Aribisala BS Bastin ME, et al: Brain white matter damage in aging and cognitive ability in youth and older age. Neurobiol Aging 34: 2740-2747, 2013

24. Vontell R, Supramaniam V, Wyatt-Ashmead J, Gressens P, Rutherford M, Hagberg H and Thornton C: Cellular mechanisms of toll-like receptor-3 activation in the thalamus are associated with white matter injury in the developing brain. J Neuropathol Exp Neurol 74: 273-285, 2015.

25. Linden JR, Ma Y, Zhao B, Harris JM, Rumah KR, Schaeren-Wiemers $\mathrm{N}$ and Vartanian T: Clostridium perfringens epsilon toxin causes selective death of mature oligodendrocytes and central nervous system demyelination. MBio 6: e02513, 2015.

26. Park E, Velumian AA and Fehlings MG: The role of excitotoxicity in secondary mechanisms of spinal cord injury: A review with an emphasis on the implications for white matter degeneration. J Neurotrauma 21: 754-774, 2004.

27. Fischer LR, Culver DG, Tennant $P$, Davis AA, Wang M, Castellano-Sanchez A, Khan J, Polak MA and Glass JD: Amyotrophic lateral sclerosis is a distal axonopathy: Evidence in mice and man. Exp Neurol 185: 232-240, 2004.

28. Nonneman A, Robberecht W and Van Den Bosch L: The role of oligodendroglial dysfunction in amyotrophic lateral sclerosis. Neurodegener Dis Manag 4: 223-239, 2014.

29. Alonso-Lana S, Goikolea JM, Bonnin CM, Sarró S, Segura B, Amann BL, Monté GC, Moro N, Fernandez-Corcuera P, Maristany T, et al: Structural and functional brain correlates of cognitive impairment in euthymic patients with bipolar disorder PLoS One 11: e0158867, 2016.

30. Bede P, Elamin M, Byrne S and Hardiman O: Sexual dimorphism in ALS: Exploring gender-specific neuroimaging signatures. Amyotroph Lateral Scler Frontotemporal Degener 15: 235-243, 2014.

31. Pryce G and Baker D: Endocannabinoids in multiple sclerosis and amyotrophic lateral sclerosis. Handb Exp Pharmacol 231: 213-231, 2015.

32. Compston A and Coles A: Multiple sclerosis. Lancet 359: $1221-1231,2002$

33. Wijesekera LC and Leigh PN: Amyotrophic lateral sclerosis Orphanet J Rare Dis 4: 3, 2009.

34. KhorshidAhmad T, Acosta C, Cortes C, Lakowski TM, Gangadaran S and Namaka M: Transcriptional Regulation of Brain-Derived Neurotrophic Factor (BDNF) by Methyl $\mathrm{CpG}$ Binding Protein 2 (MeCP2): A Novel Mechanism for Re-Myelination and/or Myelin Repair Involved in the Treatment of Multiple Sclerosis (MS). Mol Neurobiol 53: 1092-1107, 2016.

35. Zhu W, Frost EE, Begum F, Vora P, Au K, Gong Y, MacNeil B, Pillai $\mathrm{P}$ and Namaka M: The role of dorsal root ganglia activation and brain-derived neurotrophic factor in multiple sclerosis. J Cell Mol Med 16: 1856-1865, 2012.

36. Ebers GC: MS and autoimmune disorders. Neurogenetics 10: 1-3, 2009.

37. Etemadifar M, Abtahi SH, Akbari M and Maghzi AH: Multiple sclerosis and amyotrophic lateral sclerosis: Is there a link? Mult Scler 18: 902-904, 2012.

38. Saresella M, Piancone F, Tortorella P, Marventano I, Gatti A, Caputo D, Lunetta C, Corbo M, Rovaris M and Clerici M: $\mathrm{T}$ helper-17 activation dominates the immunologic milieu of both amyotrophic lateral sclerosis and progressive multiple sclerosis Clin Immunol 148: 79-88, 2013.

39. Schirmer L, Antel JP, Brück W and Stadelmann C: Axonal loss and neurofilament phosphorylation changes accompany lesion development and clinical progression in multiple sclerosis. Brain Pathol 21: 428-440, 2011

40. Wang Y, Liu G, Hong D, Chen F, Ji X and Cao G: White matter injury in ischemic stroke. Prog Neurobiol 141: 45-60, 2016

41. Matute $\mathrm{C}$ and Ransom BR: Roles of white matter in central nervous system pathophysiologies. ASN Neuro 4: pii: e00079, 2012.

42. Purger D, Gibson EM and Monje M: Myelin plasticity in the central nervous system. Neuropharmacology 110: 563-573, 2016

43. Hartline DK: What is myelin? Neuron Glia Biol 4: 153-163, 2008.

44. Debanne D, Campanac E, Bialowas A, Carlier E and Alcaraz G: Axon physiology. Physiol Rev 91: 555-602, 2011
45. Edgar JM and Nave KA: The role of CNS glia in preserving axon function. Curr Opin Neurobiol 19: 498-504, 2009.

46. Franklin RJ and Ffrench-Constant C: Remyelination in the CNS : From biology to therapy. Nat Rev Neurosci 9: 839-855, 2008.

47. Stadelmann C: Multiple sclerosis as a neurodegenerative disease: Pathology, mechanisms and therapeutic implications. Curr Opin Neurol 24: 224-229, 2011.

48. Agosta F, Pievani M, Sala S, Geroldi C, Galluzzi S, Frisoni GB and Filippi M: White matter damage in Alzheimer disease and its relationship to gray matter atrophy. Radiology 258: 853-863, 2011.

49. Chew LJ, Fusar-Poli P and Schmitz T: Oligodendroglial alterations and the role of microglia in white matter injury: Relevance to schizophrenia. Dev Neurosci 35: 102-129, 2013

50. Kumar A and Cook IA: White matter injury, neural connectivity and the pathophysiology of psychiatric disorders. Dev Neurosci 24: 255-261, 2002.

51. Menke RA, Gray E, Lu CH, Kuhle J, Talbot K, Malaspina A and Turner MR: CSF neurofilament light chain reflects corticospinal tract degeneration in ALS. Ann Clin Transl Neurol 2: 748-755, 2015.

52. Ferraiuolo L, Meyer K, Sherwood TW, Vick J, Likhite S, Frakes A, Miranda CJ, Braun L, Heath PR, Pineda R, et al: Oligodendrocytes contribute to motor neuron death in ALS via SOD1-dependent mechanism. Proc Natl Acad Sci USA 113: E6496-E6505, 2016.

53. Kang SH, Li Y, Fukaya M, Lorenzini I, Cleveland DW, Ostrow LW, Rothstein JD and Bergles DE: Degeneration and impaired regeneration of gray matter oligodendrocytes in amyotrophic lateral sclerosis. Nat Neurosci 16: 571-579, 2013.

54. Barateiro A, Brites D and Fernandes A: Oligodendrocyte development and myelination in neurodevelopment: Molecular mechanisms in health and disease. Curr Pharm Des 22: 656-679, 2016.

55. Zarei S, Carr K, Reiley L, Diaz K, Guerra O, Altamirano PF, Pagani W, Lodin D, Orozco G and Chinea A: A comprehensive review of amyotrophic lateral sclerosis. Sur Neurol Int 6: 171, 2015.

56. Renton AE, Majounie E, Waite A, Simón-Sánchez J, Rollinson S, Gibbs JR, Schymick JC, Laaksovirta H, van Swieten JC, Myllykangas L, et al: A hexanucleotide repeat expansion in C9ORF72 is the cause of chromosome 9p21-linked ALS-FTD. Neuron 72: 257-268, 2011.

57. Rosen DR, Siddique T, Patterson D, Figlewicz DA, Sapp P, Hentati A, Donaldson D, Goto J, O'Regan JP, Deng HX, et al: Mutations in $\mathrm{Cu} / \mathrm{Zn}$ superoxide dismutase gene are associated with familial amyotrophic lateral sclerosis. Nature 362: 59-62, 1993.

58. Bannwarth S, Ait-El-Mkadem S, Chaussenot A, Genin EC, Lacas-Gervais S, Fragaki K, Berg-Alonso L, Kageyama Y, Serre V, Moore DG, et al: A mitochondrial origin for frontotemporal dementia and amyotrophic lateral sclerosis through CHCHD10 involvement. Brain 137: 2329-2345, 2014.

59. Johnson JO, Pioro EP, Boehringer A, Chia R, Feit H, Renton AE, Pliner HA, Abramzon Y, Marangi G, Winborn BJ, et al: Mutations in the Matrin 3 gene cause familial amyotrophic lateral sclerosis. Nat Neurosci 17: 664-666, 2014.

60. Cirulli ET, Lasseigne BN, Petrovski S, Sapp PC, Dion PA, Leblond CS, Couthouis J, Lu YF, Wang Q, Krueger BJ, et al: Exome sequencing in amyotrophic lateral sclerosis identifies risk genes and pathways. Science 347: 1436-1441, 2015.

61. Neumann M, Sampathu DM, Kwong LK, Truax AC, Micsenyi MC, Chou TT, Bruce J, Schuck T, Grossman M, Clark CM, et al: Ubiquitinated TDP-43 in frontotemporal lobar degeneration and amyotrophic lateral sclerosis. Science 314 130-133, 2006.

62. Kwiatkowski TJ Jr, Bosco DA, Leclerc AL, Tamrazian E, Vanderburg CR, Russ C, Davis A, Gilchrist J, Kasarskis EJ, Munsat T, et al: Mutations in the FUS/TLS gene on chromosome 16 cause familial amyotrophic lateral sclerosis. Science 323: 1205-1208, 2009.

63. Maruyama $\mathrm{H}$, Morino $\mathrm{H}$, Ito $\mathrm{H}$, Izumi $\mathrm{Y}$, Kato $\mathrm{H}$, Watanabe $\mathrm{Y}$, Kinoshita Y, Kamada M, Nodera H, Suzuki H, et al: Mutations of optineurin in amyotrophic lateral sclerosis. Nature 465: 223-226, 2010.

64. Johnson JO, Mandrioli J, Benatar M, Abramzon Y, Van Deerlin VM, Trojanowski JQ, Gibbs JR, Brunetti M, Gronka S, Wuu J, et al: Exome sequencing reveals VCP mutations as a cause of familial ALS. Neuron 68: 857-864, 2010. 
65. Deng HX, Chen W, Hong ST, Boycott KM, Gorrie GH, Siddique N, Yang Y, Fecto F, Shi Y, Zhai H, et al: Mutations in UBQLN2 cause dominant X-linked juvenile and adult-onset ALS and ALS/dementia. Nature 477: 211-215, 2011.

66. Fecto F, Yan J, Vemula SP, Liu E, Yang Y, Chen W, Zheng JG Shi Y, Siddique N, Arrat H, et al: SQSTM1 mutations in familial and sporadic amyotrophic lateral sclerosis. Arch Neurol 68: 1440-1446, 2011

67. Renton AE, Chiò A and Traynor BJ: State of play in amyotrophic lateral sclerosis genetics. Nat Neurosci 17: 17-23, 2014.

68. Wu CH, Fallini C, Ticozzi N, Keagle PJ, Sapp PC, Piotrowska K, Lowe P, Koppers M, McKenna-Yasek D, Baron DM, et al: Mutations in the profilin 1 gene cause familial amyotrophic lateral sclerosis. Nature 488: 499-503, 2012.

69. Kenna KP, van Doormaal PT, Dekker AM, Ticozzi N, Kenna BJ, Diekstra FP, van Rheenen W, van Eijk KR, Jones AR, Keagle $\mathrm{P}$, et al: NEK1 variants confer susceptibility to amyotrophic lateral sclerosis. Nat Genet 48: 1037-1042, 2016.

70. Sica RE, Nicola AF, González Deniselle MC, Rodriguez G, Monachelli GM,Peralta LM and Bettini M: Sporadic amyotrophic lateral sclerosis: New hypothesis regarding its etiology and pathogenesis suggests that astrocytes might be the primary target hosting a still unknown external agent. Arq Neuropsiquiatr 69: 699-706, 2011

71. Dib M: Amyotrophic lateral sclerosis: Progress and prospects for treatment. Drugs 63: 289-310, 2003.

72. Libro R, Bramanti P and Mazzon E: The role of the Wnt canonical signaling in neurodegenerative diseases. Life Sci 158: 78-88, 2016.

73. Abdelhak A, Junker A, Brettschneider J, Kassubek J, Ludolph AC Otto $\mathrm{M}$ and Tumani H: Brain-specific cytoskeletal damage markers in cerebrospinal fluid: is there a common pattern between amyotrophic lateral sclerosis and primary progressive multiple sclerosis? Int J Mol Sci 16: 17565-17588, 2015.

74. Osellame LD, Blacker TS and Duchen MR: Cellular and molecular mechanisms of mitochondrial function. Best Pract Res Clin Endocrinol Metab 26: 711-723, 2012.

75. Duchen MR: Roles of mitochondria in health and disease Diabetes 53 (Suppl 1): S96-S102, 2004

76. Santa-Cruz LD, Guerrero-Castillo S, Uribe-Carvajal S and Tapia R: Mitochondrial dysfunction during the early stages of excitotoxic spinal motor neuron degeneration in vivo. ACS Chem Neurosci 7: 886-896, 2016.

77. Guo C, Sun L, Chen X and Zhang D: Oxidative stress, mitochondrial damage and neurodegenerative diseases. Neural Regen Res 8: 2003-2014, 2013

78. Pardillo-Díaz R, Carrascal L, Muñoz MF, Ayala A and Nunez-Abades P: Time and dose dependent effects of oxidative stress induced by cumene hydroperoxide in neuronal excitability of rat motor cortex neurons. Neurotoxicology 53: 201-214, 2016.

79. Kaal EC, Veldman H, Sodaar P, Joosten EA and Dop Bär PR: Oxidant treatment causes a dose-dependent phenotype of apoptosis in cultured motoneurons. J Neurosci Res 54: 778-786, 1998

80. Lin MT and Beal MF: Mitochondrial dysfunction and oxidative stress in neurodegenerative diseases. Nature 443: 787-795, 2006

81. Sharma A, Varghese AM, Vijaylakshmi K, Sumitha R, Prasanna VK, Shruthi S, Chandrasekhar Sagar BK, Datta KK, Gowda H, Nalini A, et al: Cerebrospinal fluid from sporadic amyotrophic lateral sclerosis patients induces mitochondrial and lysosomal dysfunction. Neurochem Res 41: 965-984, 2016.

82. Miquel E, Cassina A, Martínez-Palma L, Bolatto C, Trías E, Gandelman M, Radi R, Barbeito L and Cassina P: Modulation of astrocytic mitochondrial function by dichloroacetate improves survival and motor performance in inherited amyotrophic lateral sclerosis. PLoS One 7: e34776, 2012.

83. Liu D, Wen J, Liu J and Li L: The roles of free radicals in amyotrophic lateral sclerosis: Reactive oxygen species and elevated oxidation of protein, DNA, and membrane phospholipids FASEB J 13: 2318-2328, 1999.

84. Turner BJ and Talbot K: Transgenics, toxicity and therapeutics in rodent models of mutant SOD1-mediated familial ALS. Prog Neurobiol 85: 94-134, 2008.

85. Boillée S, Vande Velde C and Cleveland DW: ALS: A disease of motor neurons and their nonneuronal neighbors. Neuron 52: 39-59, 2006

86. Hayashi Y, Homma K and Ichijo H: SOD1 in neurotoxicity and its controversial roles in SOD1 mutation-negative ALS. Adv Biol Regul 60: 95-104, 2016.

87. Carri MT, Valle C, Bozzo F and Cozzolino M: Oxidative stress and mitochondrial damage: Importance in non-SOD1 ALS. Front Cell Neurosci 9: 41, 2015.
88. Jaronen M, Goldsteins G and Koistinaho J: ER stress and unfolded protein response in amyotrophic lateral sclerosis-a controversial role of protein disulphide isomerase. Front Cell Neurosci 8: 402, 2014.

89. Karademir B, Corek C and Ozer NK: Endoplasmic reticulum stress and proteasomal system in amyotrophic lateral sclerosis. Free Radic Biol Med 88: 42-50, 2015.

90. Sundaramoorthy V, Sultana JM and Atkin JD: Golgi fragmentation in amyotrophic lateral sclerosis, an overview of possible triggers and consequences. Front Neurosci 9: 400, 2015.

91. Atkin JD, Farg MA, Soo KY, Walker AK, Halloran M, Turner BJ, Nagley P and Horne MK: Mutant SOD1 inhibits ER-Golgi transport in amyotrophic lateral sclerosis. J Neurochem 129: 190-204, 2014

92. Parakh S and Atkin JD: Protein folding alterations in amyotrophic lateral sclerosis. Brain Res 1648: 633-649, 2016.

93. Kalmar B, Lu CH and Greensmith L: The role of heat shock proteins in Amyotrophic Lateral Sclerosis: The therapeutic potential of Arimoclomol. Pharmacol Ther 141: 40-54, 2014.

94. Rathnasamy G, Murugan M, Ling EA and Kaur C: Hypoxia-induced iron accumulation in oligodendrocytes mediates apoptosis by eliciting endoplasmic reticulum stress. Mol Neurobiol 53: 4713-4727, 2016.

95. Naughton MC, McMahon JM and FitzGerald U: Differential activation of ER stress pathways in myelinating cerebellar tracts. Int J Dev Neurosci 47: 347-360, 2015.

96. Underwood CK, Kurniawan ND, Butler TJ, Cowin GJ and Wallace RH: Non-invasive diffusion tensor imaging detects white matter degeneration in the spinal cord of a mouse model of amyotrophic lateral sclerosis. NeuroImage 55: 455-461, 2011.

97. Jaronen M, Vehviläinen P, Malm T, Keksa-Goldsteine V, Pollari E, Valonen P, Koistinaho J and Goldsteins G: Protein disulfide isomerase in ALS mouse glia links protein misfolding with NADPH oxidase-catalyzed superoxide production. Hum Mol Genet 22: 646-655, 2013

98. Saxena S, Cabuy E and Caroni P: A role for motoneuron subtype-selective ER stress in disease manifestations of FALS mice. Nat Neurosci 12: 627-636, 2009.

99. King AE, Woodhouse A, Kirkcaldie MT and Vickers JC: Excitotoxicity in ALS: Overstimulation, or overreaction? Exp Neurol 275 Pt 1: 162-171, 2016.

100. Blizzard CA, Southam KA, Dawkins E, Lewis KE, King AE, Clark JA and Dickson TC: Identifying the primary site of pathogenesis in amyotrophic lateral sclerosis-vulnerability of lower motor neurons to proximal excitotoxicity. Dis Model Mech 8: $215-224,2015$

101. Foerster BR, Pomper MG, Callaghan BC, Petrou M, Edden RA, Mohamed MA, Welsh RC, Carlos RC, Barker PB and Feldman EL: An imbalance between excitatory and inhibitory neurotransmitters in amyotrophic lateral sclerosis revealed by use of 3-T proton magnetic resonance spectroscopy. JAMA Neurol 70: 1009-1016, 2013

102. Cooper AJ: The role of glutamine synthetase and glutamate dehydrogenase in cerebral ammonia homeostasis. Neurochem Res 37: 2439-2455, 2012.

103. Matyja E, Taraszewska A, Nagańska E, Rafałowska J and Gebarowska J: Astroglial alterations in amyotrophic lateral sclerosis (ALS) model of slow glutamate excitotoxicity in vitro. Folia Neuropathol 44: 183-190, 2006

104. King AE, Dickson TC, Blizzard CA, Foster SS, Chung RS, West AK, Chuah MI and Vickers JC: Excitotoxicity mediated by non-NMDA receptors causes distal axonopathy in long-term cultured spinal motor neurons. Eur J Neurosci 26: 2151-2159, 2007.

105. Gressens P: VIP neuroprotection against excitotoxic lesions of the developing mouse brain. Ann N Y Acad Sci 897: 109-124, 1999.

106. Passemard S, Sokolowska P, Schwendimann L and Gressens P: VIP-induced neuroprotection of the developing brain. Curr Pharm Des 17: 1036-1039, 2011.

107. Lee J, Hyeon SJ, Im H, Ryu H, Kim Y and Ryu H: Astrocytes and microglia as non-cell autonomous players in the pathogenesis of ALS. Exp Neurobiol 25: 233-240, 2016.

108. Ludwin SK, Rao VTs, Moore CS and Antel JP: Astrocytes in multiple sclerosis. Mult Scler 22: 1114-1124, 2016.

109. Takimoto M and Hamada T: Acute exercise increases brain region-specific expression of MCT1, MCT2, MCT4, GLUT1, and COX IV proteins. J Appl Physiol (1985) 116: 1238-1250, 2014 
110. Lundgaard I, Osório MJ, Kress BT, Sanggaard S and Nedergaard M: White matter astrocytes in health and disease. Neuroscience 276: 161-173, 2014.

111. Morrison BM, Lee Y and Rothstein JD: Oligodendroglia: Metabolic supporters of axons. Trends Cell Biol 23: 644-651,2013.

112. Philips T, Bento-Abreu A, Nonneman A, Haeck W, Staats K, Geelen V, Hersmus N, Küsters B, Van Den Bosch L, Van Damme P, et al: Oligodendrocyte dysfunction in the pathogenesis of amyotrophic lateral sclerosis. Brain 136: 471-482, 2013

113. Fünfschilling U, Supplie LM, Mahad D, Boretius S, Saab AS Edgar J, Brinkmann BG, Kassmann CM, Tzvetanova ID, Möbius W, et al: Glycolytic oligodendrocytes maintain myelin and long-term axonal integrity. Nature 485: 517-521, 2012.

114. Lee Y, Morrison BM, Li Y,Lengacher S, Farah MH, Hoffman PN, Liu Y, Tsingalia A, Jin L, Zhang PW, et al: Oligodendroglia metabolically support axons and contribute to neurodegeneration. Nature 487: 443-448, 2012.

115. Pierre K and Pellerin L: Monocarboxylate transporters in the central nervous system: Distribution, regulation and function. J Neurochem 94: 1-14, 2005.

116. Nijland PG, Michailidou I, Witte ME, Mizee MR, van der Pol SM, van Het Hof B, Reijerkerk A, Pellerin L, van der Valk P, de Vries HE and van Horssen J: Cellular distribution of glucose and monocarboxylate transporters in human brain white matter and multiple sclerosis lesions. Glia 62: 1125-1141, 2014.

117. Robinet C and Pellerin L: Brain-derived neurotrophic factor enhances the expression of the monocarboxylate transporter 2 through translational activation in mouse cultured cortical neurons. J Cereb Blood Flow Metab 30: 286-298, 2010.

118. Lemmens R, Van Hoecke A, Hersmus N, Geelen V, D'Hollander I, Thijs V, Van Den Bosch L, Carmeliet P and Robberecht W: Overexpression of mutant superoxide dismutase 1 causes a motor axonopathy in the zebrafish. Hum Mol Genet 16 : $2359-2365,2007$

119. Wong M and Martin LJ: Skeletal muscle-restricted expression of human SOD1 causes motor neuron degeneration in transgenic mice. Hum Mol Genet 19: 2284-2302, 2010.

120. Sotelo-Silveira JR, Lepanto P, Elizondo V, Horjales S, Palacios F, Martinez-Palma L, Marin M, Beckman JS and Barbeito L: Axonal mitochondrial clusters containing mutant SOD1 in transgenic models of ALS. Antioxid Redox Signal 11: $1535-1545,2009$.

121. King AE, Dickson TC, Blizzard CA, Woodhouse A, Foster SS, Chung RS and Vickers JC: Neuron-glia interactions underlie ALS-like axonal cytoskeletal pathology. Neurobiol Aging 32: 459-469, 2011.

122. Frey D, Schneider C, Xu L, Borg J, Spooren W and Caroni P: Early and selective loss of neuromuscular synapse subtypes with low sprouting competence in motoneuron diseases. J Neurosci 20: 2534-2542, 2000.

123. Nave KA and Trapp BD: Axon-glial signaling and the glial support of axon function. Annu Rev Neurosci 31: 535-561, 2008.

124. Anderson JE, Do MQ, Daneshvar N, Suzuki T, Dort J, Mizunoya W and Tatsumi R: The role of semaphorin3A in myogenic regeneration and the formation of functional neuromuscular junctions on new fibres. Biol Rev Camb Philos Soc: Jun 13, 2016 (Epub ahead of print).

125. Syed YA, Hand E, Möbius W, Zhao C, Hofer M, Nave KA and Kotter MR: Inhibition of CNS remyelination by the presence of semaphorin 3A. J Neurosci 31: 3719-3728, 2011.

126. Spassky N, de Castro F, Le Bras B, Heydon K, Quéraud-LeSaux F, Bloch-Gallego E, Chédotal A, Zalc B and Thomas JL: Directional guidance of oligodendroglial migration by class 3 semaphorins and netrin-1. J Neurosci 22: 5992-6004, 2002.

127. Piaton G, Aigrot MS, Williams A, Moyon S, Tepavcevic V, Moutkine I, Gras J, Matho KS, Schmitt A, Soellner H, et al: Class 3 semaphorins influence oligodendrocyte precursor recruitment and remyelination in adult central nervous system. Brain 134: 1156-1167, 2011

128. Venkova K, Christov A, Kamaluddin Z, Kobalka P, Siddiqui S and Hensley K: Semaphorin 3A signaling through neuropilin-1 is an early trigger for distal axonopathy in the SOD1G93A mouse model of amyotrophic lateral sclerosis. J Neuropathol Exp Neurol 73: 702-713, 2014.

129. Korner S, Böselt S, Wichmann K, Thau-Habermann N, Zapf A, Knippenberg S, Dengler R and Petri S: The Axon Guidance Protein Semaphorin 3A Is increased in the motor cortex of patients with amyotrophic lateral sclerosis. J Neuropathol Exp Neurol: Feb 25, 2016 (Epub ahead of print).
130. Mecollari V, Nieuwenhuis B and Verhaagen J: A perspective on the role of class III semaphorin signaling in central nervous system trauma. Front Cell Neurosci 8: 328, 2014.

131. Dadon-Nachum M, Melamed E and Offen D: The 'dying-back' phenomenon of motor neurons in ALS. J Mol Neurosci 43 470-477, 2011.

132. Tao S, Yang X, Chen Y, Wang X, Xiao Z, Wang H, Wu Q and Wang X: Up-regulated methyl CpG binding protein-2 in intractable temporal lobe epilepsy patients and a rat model. Neurochem Res 37: 1886-1897, 2012.

133. Dastidar SG, Bardai FH, Ma C, Price V, Rawat V, Verma P, Narayanan V and D'Mello SR: Isoform-specific toxicity of Mecp 2 in postmitotic neurons: Suppression of neurotoxicity by FoxG1. J Neurosci 32: 2846-2855, 2012.

134. Dastidar SG, Landrieu PM and D'Mello SR: FoxG1 promotes the survival of postmitotic neurons. J Neurosci 31: 402-413, 2011.

135. Schulte-Herbrüggen O, Braun A, Rochlitzer S Jockers-Scherübl MC and Hellweg R: Neurotrophic factors-a tool for therapeutic strategies in neurological, neuropsychiatric and neuroimmunological diseases? Curr Med Chem 14: 2318-2329, 2007.

136. Cellerino A, Carroll P, Thoenen $\mathrm{H}$ and Barde YA: Reduced size of retinal ganglion cell axons and hypomyelination in mice lacking brain-derived neurotrophic factor. Mol Cell Neurosci 9: 397-408, 1997

137. Tremolizzo L, Pellegrini A, Conti E, Arosio A, Gerardi F, Lunetta C, Magni P, Appollonio I and Ferrarese C: BDNF serum levels with respect to multidimensional assessment in amyotrophic lateral sclerosis. Neurodegener Dis 16: 192-198, 2016.

138. Giménez y Ribotta M, Revah F, Pradier L, Loquet I, Mallet J and Privat A: Prevention of motoneuron death by adenovirus-mediated neurotrophic factors. J Neurosci Res 48: 281-285, 1997.

139. Dadon-Nachum M, Ben-Yaacov K, Ben-Zur T, Barhum Y, Yaffe D, Perlson E and Offen D: Transplanted modified muscle progenitor cells expressing a mixture of neurotrophic factors delay disease onset and enhance survival in the SOD1 mouse model of ALS. J Mol Neurosci 55: 788-797, 2015.

140. Xu R, Wu C, Zhang X, Zhang Q, Yang Y, Yi J, Yang R and Tao Y: Linking hypoxic and oxidative insults to cell death mechanisms in models of ALS. Brain Res 1372: 133-144, 2011.

141. Oh YK, Shin KS and Kang SJ: AIF translocates to the nucleus in the spinal motor neurons in a mouse model of ALS. Neurosci Lett 406: 205-210, 2006.

142. Pedrini S, Sau D, Guareschi S, Bogush M, Brown RH Jr, Naniche N, Kia A, Trotti D and Pasinelli P: ALS-linked mutant SOD1 damages mitochondria by promoting conformational changes in Bcl-2. Hum Mol Genet 19: 2974-2986, 2010.

143. Troost D, Aten J, Morsink F and de Jong JM: Apoptosis in amyotrophic lateral sclerosis is not restricted to motor neurons. $\mathrm{Bcl}-2$ expression is increased in unaffected post-central gyrus. Neuropathol Appl Neurobiol 21: 498-504, 1995.

144. Petrik MS, Wilson JM, Grant SC, Blackband SJ, Tabata RC, Shan X, Krieger C and Shaw CA: Magnetic resonance microscopy and immunohistochemistry of the CNS of the mutant SOD murine model of ALS reveals widespread neural deficits. Neuromolecular Med 9: 216-229, 2007.

145. Nagai M, Re DB, Nagata T, Chalazonitis A, Jessell TM, Wichterle $\mathrm{H}$ and Przedborski S: Astrocytes expressing ALS-linked mutated SOD1 release factors selectively toxic to motor neurons. Nat Neurosci 10: 615-622, 2007.

146. Guégan C and Przedborski S: Programmed cell death in amyotrophic lateral sclerosis. J Clin Invest 111: 153-161, 2003.

147. Reyes NA, Fisher JK, Austgen K, VandenBerg S, Huang EJ and Oakes SA: Blocking the mitochondrial apoptotic pathway preserves motor neuron viability and function in a mouse model of amyotrophic lateral sclerosis. J Clin Invest 120: 3673-3679, 2010.

148. Vukosavic S, Dubois-Dauphin M, Romero N and Przedborski S: $\mathrm{Bax}$ and Bcl-2 interaction in a transgenic mouse model of familial amyotrophic lateral sclerosis. J Neurochem 73: 2460-2468, 1999

149. Peviani M, Tortarolo M, Battaglia E, Piva R and Bendotti C: Specific induction of Akt3 in spinal cord motor neurons is neuroprotective in a mouse model of familial amyotrophic lateral sclerosis. Mol Neurobiol 49: 136-148, 2014

150. Shrivastava M and Subbiah V: Elevated caspase 3 activity and cytosolic cytochrome $\mathrm{c}$ in NT2 cybrids containing amyotrophic lateral sclerosis subject mtDNA. Int J Neurosci 126: 839-849, 2016.

151. Sathasivam S and Shaw PJ: Apoptosis in amyotrophic lateral sclerosis-what is the evidence? Lancet Neurol 4: 500-509, 2005. 
152. Tanaka H, Shimazaki H, Kimura M, Izuta H, Tsuruma K, Shimazawa $\mathrm{M}$ and Hara $\mathrm{H}$ : Apoptosis-inducing factor and cyclophilin A cotranslocate to the motor neuronal nuclei in amyotrophic lateral sclerosis model mice. CNS Neurosci Ther 17: 294-304, 2011.

153. Wang Y and Kasper LH: The role of microbiome in central nervous system disorders. Brain Behav Immun 38: 1-12, 2014.

154. Glenn JD and Mowry EM: Emerging Concepts on the Gut Microbiome and Multiple Sclerosis. J Interferon Cytokine Res 36: 347-357, 2016.

155. Bhargava P and Mowry EM: Gut microbiome and multiple sclerosis. Curr Neurol Neurosci Rep 14: 492, 2014.

156. Luna RA, Savidge TC and Williams KC: The Brain-Gut-Microbiome Axis: What Role Does It Play in Autism Spectrum Disorder? Curr Dev Disord Rep 3: 75-81, 2016.

157. Fang X: Potential role of gut microbiota and tissue barriers in Parkinson's disease and amyotrophic lateral sclerosis. Int J Neurosci 126: 771-776, 2016.

158. Galland L: The gut microbiome and the brain. J Med Food 17: 1261-1272, 2014.

159. Newland PK, Heitkemper M and Zhou Y: The Emerging Role of the Gut Microbiome in Adult Patients With Multiple Sclerosis. J Neurosci Nurs 48: 358-364, 2016

160. Chen J, Chia N, Kalari KR, Yao JZ, Novotna M, Soldan MM, Luckey DH, Marietta EV, Jeraldo PR, Chen X, et al: Multiple sclerosis patients have a distinct gut microbiota compared to healthy controls. Sci Rep 6: 28484, 2016.

161. Kaneko K and Hachiya NS: Hypothesis: Gut as source of motor neuron toxin in the development of ALS. Med Hypotheses 66 : 438-439, 2006.

162. Longstreth WT Jr, Meschke JS, Davidson SK, Smoot LM, Smoot JC and Koepsell TD: Hypothesis: A motor neuron toxin produced by a clostridial species residing in gut causes ALS Med Hypotheses 64: 1153-1156, 2005.

163. Wu S, Yi J, Zhang YG, Zhou J and Sun J: Leaky intestine and impaired microbiome in an amyotrophic lateral sclerosis mouse model. Physiol Rep 3: pii: e12356, 2015.

164. Miller RG, Mitchell JD and Moore DH: Riluzole for amyotrophic lateral sclerosis (ALS)/motor neuron disease (MND). Cochrane Database Syst Rev: CD001447, 2012.

165. Cetin H, Rath J, Füzi J, Reichardt B, Fülöp G, Koppi S, Erdler M Ransmayr G, Weber J, Neumann K, et al: Epidemiology of amyotrophic lateral sclerosis and effect of riluzole on disease course. Neuroepidemiology 44: 6-15, 2015.

166. Vucic S, Lin CS, Cheah BC, Murray J, Menon P, Krishnan AV and Kiernan MC: Riluzole exerts central and peripheral modulating effects in amyotrophic lateral sclerosis. Brain 136: 1361-1370, 2013

167. Cheah BC, Vucic S, Krishnan AV and Kiernan MC: Riluzole, neuroprotection and amyotrophic lateral sclerosis. Curr Med Chem 17: 1942-1199, 2010.

168. Bellingham MC: A review of the neural mechanisms of action and clinical efficiency of riluzole in treating amyotrophic lateral sclerosis: What have we learned in the last decade? CNS Neurosci Ther 17: 4-31, 2011.

169. Dennys CN, Armstrong J, Levy M, Byun YJ, Ramdial KR, Bott M, Rossi FH, Fernández-Valle C, Franco MC and Estevez AG: Chronic inhibitory effect of riluzole on trophic factor production. Exp Neurol 271: 301-307, 2015.

170. Tsai SJ: Is riluzole a potential therapy for Rett syndrome? Med Hypotheses 85: 76-78, 2015.

171. Turck P and Frizzo ME: Riluzole stimulates BDNF release from human platelets. Biomed Res Int 2015: 189307, 2015.

172. Gilgun-Sherki Y, Panet H, Melamed E and Offen D: Riluzole suppresses experimental autoimmune encephalomyelitis: Implications for the treatment of multiple sclerosis. Brain Res 989: 196-204, 2003.

173. Shirani A, Okuda DT and Stüve O: Therapeutic advances and future prospects in progressive forms of multiple sclerosis. Neurotherapeutics 13: 58-69, 2016.

174. Waubant E, Maghzi AH, Revirajan N, Spain R, Julian L, Mowry EM, Marcus J, Liu S, Jin C, Green A, et al: A randomized controlled phase II trial of riluzole in early multiple sclerosis. Ann Clin Transl Neurol 1: 340-347, 2014.

175. Obata K and Noguchi K: BDNF in sensory neurons and chronic pain. Neurosci Res 55: 1-10, 2006.

176. Caumo W, Deitos A, Carvalho S, Leite J, Carvalho F, Dussán-Sarria JA, Lopes Tarragó Mda G, Souza A, Torres IL and Fregni F: Motor cortex excitability and BDNF levels in chronic musculoskeletal pain according to structural pathology. Front Hum Neurosci 10: 357, 2016
177. Gutierrez J, Federici T, Peterson B, Bartus R, Betourne A and Boulis NM: 321 development of intrathecal riluzole: A new route of administration for the treatment of amyotrophic lateral sclerosis patients. Neurosurgery 63 (Suppl 1): S193, 2016

178. Browne EC and Abbott BM: Recent progress towards an effective treatment of amyotrophic lateral sclerosis using the SOD1 mouse model in a preclinical setting. Eur J Med Chem 121 918-925, 2016

179. Lieberknecht V, Junqueira SC, Cunha MP, Barbosa TA, de Souza LF, Coelho IS, Santos AR, Rodrigues AL, Dafré AL and Dutra RC: Pramipexole, a Dopamine D2/D3 receptor-preferring agonist, prevents experimental autoimmune encephalomyelitis development in Mice. Mol Neurobiol 54 1033-1045, 2017.

180. Ferrari-Toninelli G, Maccarinelli G, Uberti D, Buerger E and Memo M: Mitochondria-targeted antioxidant effects of S(-) and $\mathrm{R}(+)$ pramipexole. BMC Pharmacol 10: 2, 2010.

181. Abramova NA, Cassarino DS, Khan SM, Painter TW and Bennett JP Jr: Inhibition by $\mathrm{R}(+)$ or $\mathrm{S}(-)$ pramipexole of caspase activation and cell death induced by methylpyridinium ion or beta amyloid peptide in SH-SY5Y neuroblastoma. J Neurosci Res 67: 494-500, 2002.

182. Alavian KN, Dworetzky SI, Bonanni L, Zhang P, Sacchetti S, Mariggio MA, Onofrj M, Thomas A, Li H, Mangold JE, et al: Effects of dexpramipexole on brain mitochondrial conductances and cellular bioenergetic efficiency. Brain Res 1446: 1-11, 2012.

183. Corcia P and Gordon PH: Amyotrophic lateral sclerosis and the clinical potential of dexpramipexole. Ther Clin Risk Manag 8: 359-366, 2012

184. De Nuccio C, Bernardo A, Cruciani C, De Simone R, Visentin S and Minghetti L: Peroxisome proliferator activated receptor- $\gamma$ agonists protect oligodendrocyte progenitors against tumor necrosis factor-alpha-induced damage: Effects on mitochondrial functions and differentiation. Exp Neurol 271: 506-514, 2015.

185. Shukla DK, Kaiser CC, Stebbins GT and Feinstein DL: Effects of pioglitazone on diffusion tensor imaging indices in multiple sclerosis patients. Neurosci Lett 472: 153-156, 2010.

186. Dupuis L, Dengler R, Heneka MT, Meyer T, Zierz S, Kassubek J, Fischer W, Steiner F, Lindauer E, Otto M, et al: A randomized, double blind, placebo-controlled trial of pioglitazone in combination with riluzole in amyotrophic lateral sclerosis. PLoS One 7: e37885, 2012.

187. Yáñez M, Matías-Guiu J, Arranz-Tagarro JA, Galán L, Viña D, Gómez-Pinedo U, Vela A, Guerrero A, Martínez-Vila E and García AG: The neuroprotection exerted by memantine, minocycline and lithium, against neurotoxicity of CSF from patients with amyotrophic lateral sclerosis, is antagonized by riluzole. Neurodegener Dis 13: 171-179, 2014.

188. Herges K, Millward JM, Hentschel N, Infante-Duarte C, Aktas O and Zipp F: Neuroprotective effect of combination therapy of glatiramer acetate and epigallocatechin-3-gallate in neuroinflammation. PLoS One 6: e25456, 2011.

189. Koh SH, Lee SM, Kim HY, Lee KY, Lee YJ, Kim HT, Kim J, Kim MH, Hwang MS, Song C, et al: The effect of epigallocatechin gallate on suppressing disease progression of ALS model mice. Neurosci Lett 395: 103-107, 2006.

190. Solanki I, Parihar P, Mansuri ML and Parihar MS: Flavonoid-based therapies in the early management of neurodegenerative diseases. Adv Nutr 6: 64-72, 2015.

191. Feng Z and Gao F: Stem cell challenges in the treatment of neurodegenerative disease. CNS Neurosci Ther 18: 142-148, 2012.

192. Nizzardo M, Simone C, Rizzo F, Ruggieri M, Salani S, Riboldi G, Faravelli I, Zanetta C, Bresolin N, Comi GP and Corti S: Minimally invasive transplantation of iPSC-derived ALDHhiSSCloVLA4+ neural stem cells effectively improves the phenotype of an amyotrophic lateral sclerosis model. Hum Mol Genet 23: 342-354, 2014.

193. Martinez HR, Gonzalez-Garza MT, Moreno-Cuevas JE, Caro E, Gutierrez-Jimenez E and Segura JJ: Stem-cell transplantation into the frontal motor cortex in amyotrophic lateral sclerosis patients. Cytotherapy 11: 26-34, 2009.

194. Einstein O, Friedman-Levi Y, Grigoriadis N and Ben-Hur T: Transplanted neural precursors enhance host brain-derived myelin regeneration. J Neurosci 29: 15694-15702, 2009.

195. Makar TK, Bever CT, Singh IS, Royal W, Sahu SN, Sura TP, Sultana S, Sura KT, Patel N, Dhib-Jalbut S and Trisler D: Brain-derived neurotrophic factor gene delivery in an animal model of multiple sclerosis using bone marrow stem cells as a vehicle. J Neuroimmunol 210: 40-51, 2009. 
196. Staines DR: Are multiple sclerosis and amyotrophic lateral sclerosis autoimmune disorders of endogenous vasoactive neuropeptides? Med Hypotheses 70: 413-418, 2008.

197. Spinelli EG, Agosta F, Ferraro PM, Riva N, Lunetta C, Falzone YM, Comi G, Falini A and Filippi M: Brain MR imaging in patients with lower motor neuron-predominant disease. Radiology 280: 545-556, 2016.

198. Prudlo J, Bissbort C, Glass A, Grossmann A, Hauenstein K, Benecke R and Teipel SJ: White matter pathology in ALS and lower motor neuron ALS variants: A diffusion tensor imaging study using tract-based spatial statistics. J Neurol 259: 1848-1859, 2012.

199. Beer A, Biberacher V, Schmidt P, Righart R, Buck D, Berthele A, Kirschke J, Zimmer C, Hemmer B and Mühlau M: Tissue damage within normal appearing white matter in early multiple sclerosis: Assessment by the ratio of T1- and T2-weighted MR image intensity. J Neurol 263: 1495-1502, 2016.
200. Gutiérrez-Franco A, Eixarch H, Costa C, Gil V, Castillo M, Calvo-Barreiro L, Montalban X, Del Río JA and Espejo C: Semaphorin 7A as a potential therapeutic target for multiple sclerosis. Mol Neurobiol: Oct 6, 2016 (Epub ahead of print).

201. Costa C, Martínez-Sáez E, Gutiérrez-Franco A, Eixarch H, Castro Z, Ortega-Aznar A, Ramón Y Cajal S, Montalban X and Espejo C: Expression of semaphorin 3A, semaphorin 7A and their receptors in multiple sclerosis lesions. Mult Scler 21: 1632-1643, 2015. 